\title{
Determination of rainfall thresholds for shallow landslides by a probabilistic and empirical method
}

\author{
J. Huang, N. P. Ju, Y. J. Liao, and D. D. Liu \\ State Key Laboratory of Geohazard Prevention and Geo-environment Protection, Chengdu University of Technology, \\ Chengdu, Sichuan 610059, China
}

Correspondence to: J. Huang (huangjian2010@gmail.com)

Received: 14 February 2015 - Published in Nat. Hazards Earth Syst. Sci. Discuss.: 27 May 2015

Accepted: 3 December 2015 - Published: 21 December 2015

\begin{abstract}
Rainfall-induced landslides not only cause property loss, but also kill and injure large numbers of people every year in mountainous areas in China. These losses and casualties may be avoided to some extent with rainfall threshold values used in an early warning system at a regional scale for the occurrence of landslides. However, the limited availability of data always causes difficulties. In this paper we present a method to calculate rainfall threshold values with limited data sets for two rainfall parameters: hourly rainfall intensity and accumulated precipitation. The method has been applied to the Huangshan region, in the province of Anhui, China. Four early warning levels (zero, outlook, attention, and warning) have been adopted and the corresponding rainfall threshold values have been defined by probability lines. A validation procedure showed that this method can significantly enhance the effectiveness of a warning system, and finally reduce and mitigate the risk of shallow landslides in mountainous regions.
\end{abstract}

\section{Introduction}

Landslide risk has increased all over the world during recent decades, because of the uncontrolled urban sprawl by fast population growth and accelerated economic development. Particularly in many mountainous regions of developing countries, such as China, natural hazards have already become one of the most significant threats to people and property. On 7 August 2010, two debris flows occurred in the Sanyanyu gully and Loujiayu gully, near the county of Zhouqu, Gansu, northwestern China, which took about 1765 people's lives of people living on the densely urban- ized fan (Tang et al., 2011). On 11 January 2013, a large landslide induced by rainfall in the county of Zhenxiong, Yunnan, killed 46 people (Yin et al., 2013). Not only in China, but also in a number of developed countries, such as the Daunia region in southern Italy, do abundant mass movements also cause a high level of potential risk to urban centers and transportation systems (Pellicani et al., 2013). In September 2004, a hurricane-induced debris flow killed five persons in North Carolina (Wooten et al., 2007), and a landslide killed 10 persons in La Conchita in January 2005 (Jibson, 2005). Additionally, the southwest of China is one of the regions most affected by more catastrophic events, where complicated geological conditions exist and earthquakes are generated (e.g., Wenchuan earthquake on 12 May 2008 and Lushan earthquake on April 20, 2013). These phenomena have illustrated the vulnerability to natural hazards, the underestimation of the potential risks; and they have revealed the lack of policies for disaster reduction and mitigation in these regions. The public and government have been sensitized to the urgent demand for effective warning systems in landslide-prone areas.

Generally, rainfall-induced shallow landslides are less than $3-5 \mathrm{~m}$ thick and move with quite a high velocity. Usually they are widespread in mountainous areas. In order to reduce this impact, more and more scientists are working on forecasting the occurrence of shallow landslides. According to the different scale of study area, this research can be classified into two categories: local studies and regional studies. For local research, first physical slope stability models must be developed to understand the instability mechanism of an individual landslide, then a monitoring system for rainfall and slope movements has to be installed, which is then followed by a comprehensive analysis of the mon- 
itoring data. For more information about single landslide early warning systems in various parts of the world, see Thiebes (2012), Carey and Petley (2014), and others. When working over larger areas, the method used in early warning systems to forecast shallow landslide occurrence is frequently based on statistical and empirical models relying on one or two parameters from the rainfall events, e.g., rainfall intensity and duration, or antecedent precipitation. Generally, there are five types of methods to obtain the threshold line for rainfall-induced shallow landslides: (i) precipitation intensity-duration (I-D) thresholds, e.g., Keefer et al. (1987), Guzzetti et al. (2007a), Cannon et al. (2008), and Segoni et al. (2014), which is perhaps the most popular among rainfall threshold methods; (ii) daily precipitation and antecedent effective rainfall, e.g., Glade et al. (2000), Guo et al. (2013); (iii) cumulative precipitation-duration thresholds, e.g., Aleotti (2004); (iv) cumulative precipitationaverage rainfall intensity thresholds, e.g., Hong et al. (2005); and (v) a combination of cumulative rainfall threshold, rainfall intensity-duration threshold and antecedent water index or soil wetness, e.g., Baum and Godt (2009). In particular, empirical rainfall thresholds have already proven their value to forecast the occurrence of landslides, and are frequently used in operational warning systems (Baum and Godt, 2009; Glade et al., 2000; Greco et al., 2013; Guzzetti et al., 2007a, b; Keefer et al. 1987; Osanai et al., 2010; Segoni et al., 2014, 2015; Wei et al., 2015; Zêzere et al., 2014). However, as shown by Intrieri et al. (2012), an early warning system (EWS) is a very complicated system. According to the United Nations International Strategy for Disaster Reduction (UNISDR, 2009), it is defined as "the set of capacities needed to generate and disseminate timely and meaningful warning information to enable individuals, communities, and organizations threatened by a hazard to prepare and to act appropriately and in sufficient time to reduce the possibility of harm or loss."

Several excellent examples of EWS have already been proposed for different regions, such as Seattle, on the west coast of the USA (Baum and Godt, 2009), the Adriatic Danubian area in central and southern Europe (Guzzetti et al., 2007b), and Xi'an, in the province of Shanxi, China (Zhuang et al., 2014). For Tuscany, Italy, Segoni et al. (2014) presented a mosaic of several local rainfall thresholds instead of a single regional one. They established a relation between the threshold parameters and the prevailing lithology, which significantly enhances the effectiveness of an early warning system. However, all these critical thresholds and equations strongly depend on the local physiographic, hydrological, and meteorological conditions (Guzzetti et al., 2007a). In addition, they suffer from the lack of necessary resources for provision of continuous support or expansion of services. The application of these methods in other regions is very difficult from a practical point of view. It is, therefore, so important and urgent to find a simple and suitable approach for the definition of warning thresholds through the study of fundamental pro-

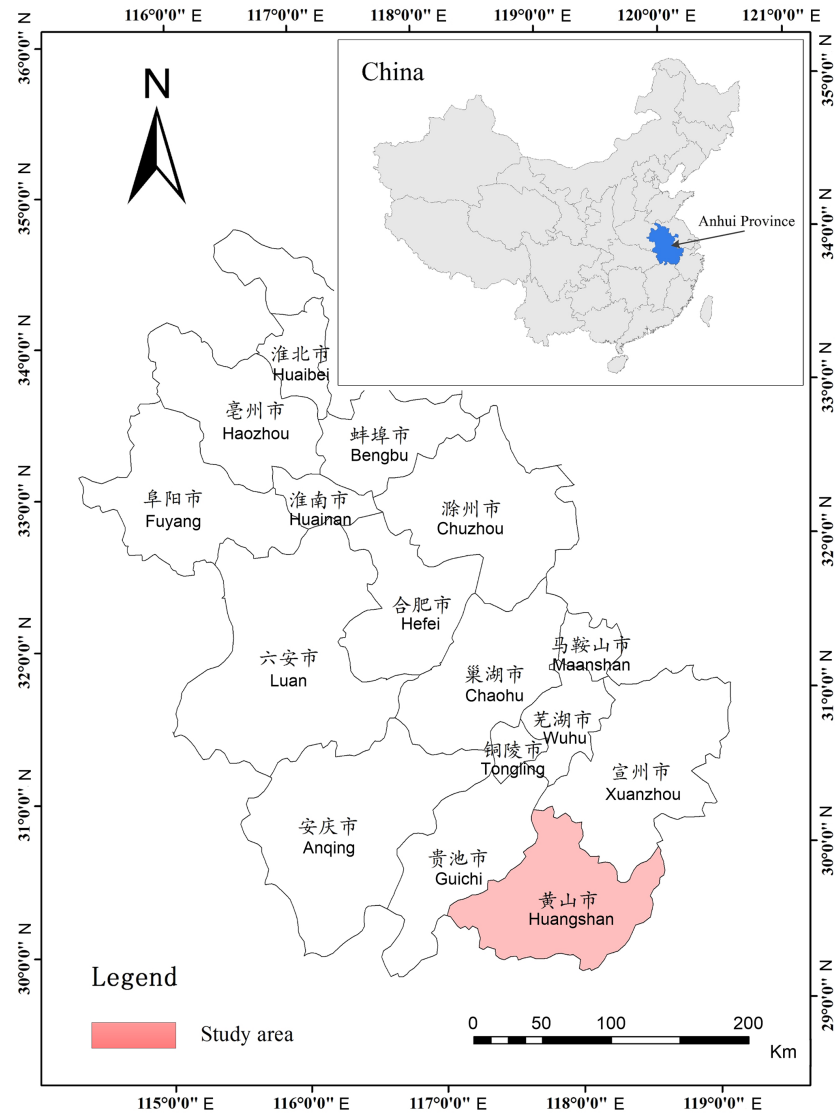

Figure 1. Location of the Huangshan region. The inset map shows the location of the province of Anhui, China.

cess mechanisms and the analysis of relationships between rainfall and landslides. Presently, most mountainous regions in China lack available rainfall records and landslide occurrence information, which makes it much more difficult to establish a rainfall threshold for landslide forecasting in a short period of time.

This paper presents the results of a recent study on rainfall thresholds for shallow landslides at a regional scale to overcome the aforementioned difficulties. The thresholds are determined with rigorous statistical techniques from two rainfall parameters. The paper contains (i) the description of a method to calculate rainfall thresholds from limited available data and time; (ii) the application and improvement of the rainfall threshold for landslide early warning in a case study.

\section{Study area}

The Huangshan study area is located in the province of Anhui, eastern China (Fig. 1), and covers an area of $9807 \mathrm{~km}^{2}$, most of which is tablelands and mountains, with elevations ranging from 1000 to $1873 \mathrm{~m}$ above sea level (a.s.l.); some areas between the mountains are at elevations lower 


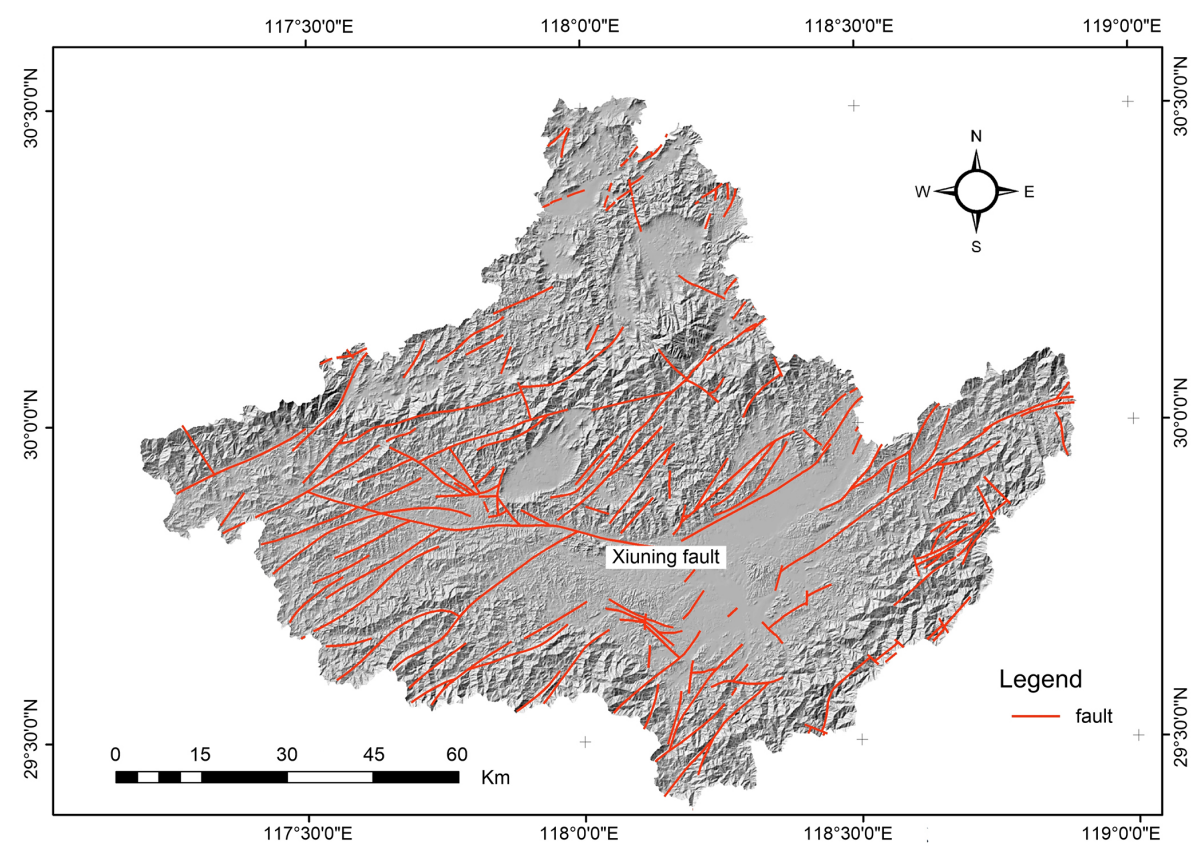

Figure 2. Faults distribution of the Huangshan region with a digital elevation model (DEM) background.

than $500 \mathrm{~m}$ a.s.l. The Huangshan region has a population of 1.47 million (in the year 2012). In the mountainous areas, the general climate is moist, monsoonal, and subtropical, with an average yearly temperature of $15.5-16.4^{\circ}$, although this is strongly dependent on the altitude, especially above $1000 \mathrm{~m}$ a.s.l. The total annual rainfall ranges from 1500 to $3100 \mathrm{~mm}$, most of which falls on the southern slopes from May to October.

The landslide-prone areas lie between the southern Yangtze Block (south of the Yangtze Plate) and the transitional segment of the Jiangnan uplift belt. The main fault zones are NE- and EW-trending which determine the local tectonics and topography, and one fault, called Xiuning fault, is inferred to separate the mountains and the hilly parts and plains, as shown in Fig. 2 (Ju et al., 2008). The rocks in the study area range from late Precambrian to Upper Triassic in age and consist mainly of granite, dolomite, limestone, sandstone, slate, and shale. The complicated geological condition, the numerous heavy rainfall events, and the numerous human activities in the area caused numerous landslides, leading to catastrophic economic losses and large numbers of fatalities in recent years.

\section{Materials and methodology}

The methodology used in this study mainly consisted of two components: (i) the collection of landslide and rainfall records and (ii) the analysis of the relationship between rainfall and landslide occurrence using probabilistic and empirical methods. Several methods have been used in this study to collect additional data for the analysis, such as those data contained in technical reports and documents produced by national scientific communities and government agencies. The parameters and analysis model are mainly referenced from previous researchers, but have been improved in this paper to present a more simple and suitable approach for shallow landslide early warning in mountainous areas.

\subsection{Landslide and rainfall data}

Detailed landslide and rainfall data sets are the foundation for the analysis of the relationship between rainfall and landslide occurrence. The landslide inventory and rainfall data provided in this paper are mostly the result of field investigations immediately after landslide occurrence, and were validated by the local geological and environmental monitoring station in the Huangshan region during the period 20072012 (Fig. 3). Most of the shallow landslides are located in the mountainous region, which always occurred in rainy season every year, but some are located in the plain areas where usually rive banks are.

In this period, more than 100 shallow landslides were recorded but some of them were not triggered by rainfall. Some landslides were triggered by factors of human activity and were not included in the study. This also applies to some events with unclear dates of occurrence. As a result, there are only 50 landslides with accurate dates of occurrence and rainfall records collected in the data sets; typical examples are shown in Table 1. Meanwhile, in order to study the relationship between rainfall and shallow landslide occurrences, 
Table 1. Typical shallow landslides triggered by rainfall in the Huangshan region.

\begin{tabular}{llllll}
\hline \multirow{2}{*}{ Name } & \multicolumn{2}{c}{ Location } & Date & $\begin{array}{l}\text { Hourly rainfall } \\
\text { intensity }\left(\mathrm{mm} \mathrm{h}^{-1}\right)\end{array}$ & $\begin{array}{l}\text { Accumulated } \\
\text { precipitation }(\mathrm{mm})\end{array}$ \\
\cline { 2 - 5 } & \multicolumn{2}{l}{ Longitude $\left({ }^{\circ} \mathrm{E}\right)$} & Latitude $\left({ }^{\circ} \mathrm{N}\right)$ & & \\
\hline Shacun & 117.9664 & 30.2511 & 10.07 .2007 & 47.1 & 268.8 \\
Dawu & 118.3710 & 29.7078 & 10.06 .2008 & 29.2 & 305.6 \\
Xiacun & 118.4139 & 29.8182 & 18.06 .2008 & 8.0 & 194.6 \\
Zaotai & 118.8294 & 29.9871 & 27.06 .2008 & 15.0 & 105.2 \\
Fenghuangshan & 118.0000 & 30.3256 & 01.08 .2008 & 12.2 & 203.4 \\
Zhoulintian & 118.2922 & 29.9009 & 28.07 .2009 & 13.5 & 243.8 \\
Yaojiapeng & 118.3231 & 29.6038 & 10.07 .2010 & 27.1 & 260.2 \\
Banxizu & 117.7440 & 30.0129 & 15.07 .2010 & 27.9 & 463.9 \\
Jinzhu & 118.5683 & 29.8837 & 09.06 .2011 & 20.7 & 204.7 \\
Yuelingwu & 118.5169 & 29.8311 & 10.06 .2011 & 15.3 & 270.7 \\
Yinshan & 118.6564 & 29.7175 & 15.06 .2011 & 16.2 & 440.6 \\
Linlangkeng & 118.2808 & 29.9186 & 19.06 .2011 & 12.7 & 323.8 \\
Hulingcun & 118.7113 & 29.8937 & 26.06 .2012 & 14.5 & 111.4 \\
Lucun & 117.9750 & 30.0154 & 08.08 .2012 & 14.1 & 23.6 \\
Hongxing & 118.1850 & 29.8042 & 11.08 .2012 & 8.7 & 189.7 \\
\hline
\end{tabular}

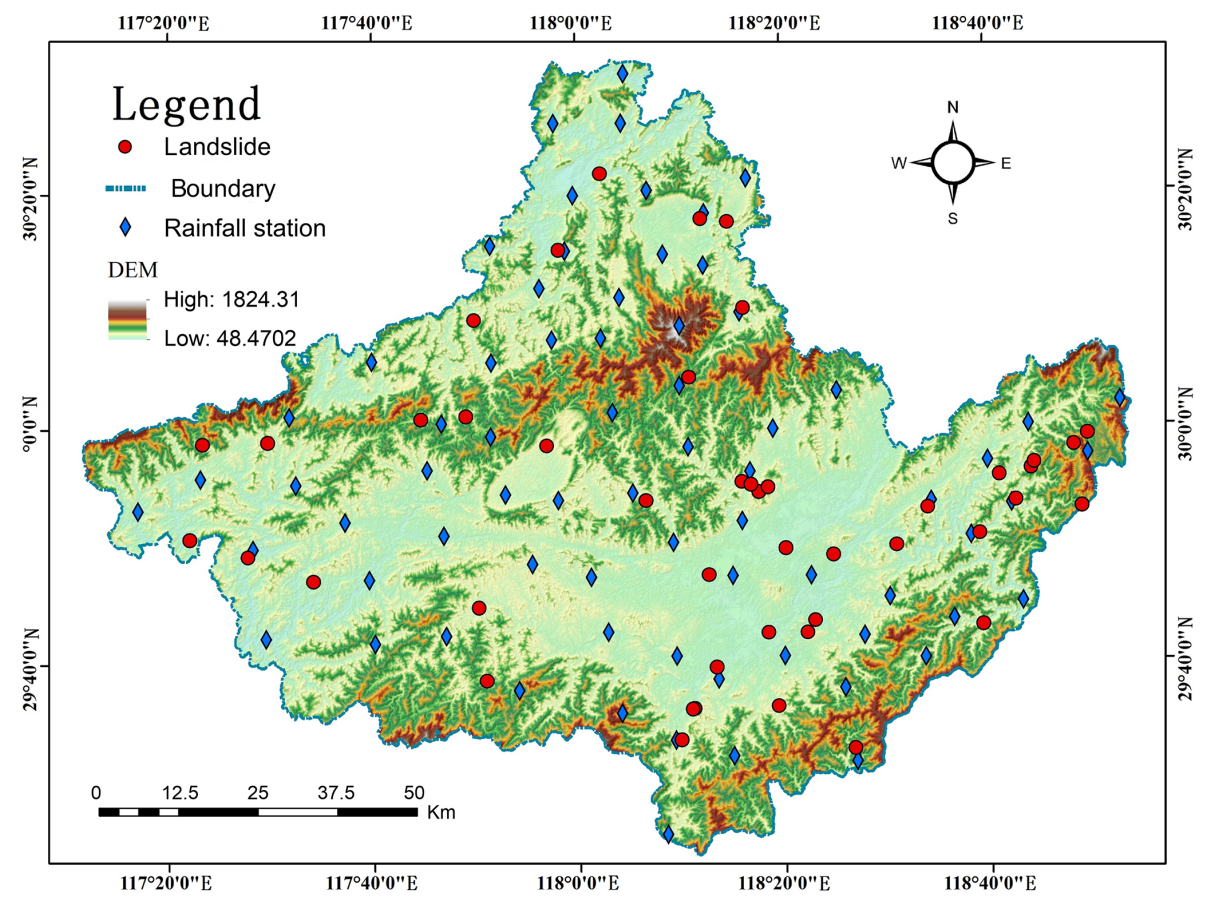

Figure 3. Location of rainfall-induced shallow landslides in the Huangshan region (2007-2012).

more than 50 historical rainfall events with no landslide occurrence were also collected for use during the analysis.

\subsection{The probabilistic and empirical model}

As mentioned in the introduction, there are several parameters related to rainfall thresholds which have been applied successfully in some regions. In the Huangshan region, it is very difficult to obtain a reliable rainfall threshold value for landslide early warning due to the limited availability of data. In order to overcome this problem, a trial method was developed first. Its practicability and expandability will be investigated with new collected data in the near future. Two rainfall parameters were selected to obtain the threshold equation in a simple way from the database that is currently available: the hourly rainfall intensity $\left(\mathrm{I}_{\mathrm{h}}: \mathrm{mm} \mathrm{h}^{-1}\right)$ and the accumu- 


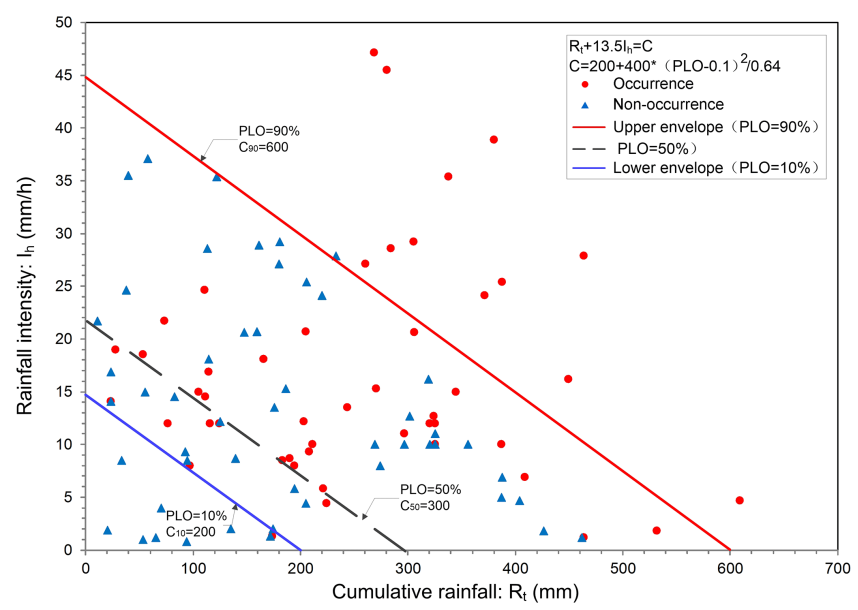

Figure 4. $R_{t}-\mathrm{I}_{\mathrm{h}}$ graph for occurrence (red points) and nonoccurrence (blue triangular points) of landslide events in the Huangshan region based on historical rainfall data.

lated precipitation $\left(R_{t}: \mathrm{mm}\right)$. Generally, the accurate time of landslide occurrence is not always definitely during a rainstorm. According to Jan et al. (2002), therefore, maximum hourly rainfall intensity in a rainfall record is calculated as the triggering parameter for rainfall threshold study. The accumulated precipitation is a total sum of rainfall amount for 7 days including that day of rainstorm occurrence for the consideration of antecedent effective rainfall.

The beginning of each rainfall event is defined as the moment that the hourly rainfall amount is more than $4 \mathrm{~mm} \mathrm{~h}^{-1}$, and the end is when the hourly rainfall amount is less than $4 \mathrm{~mm} \mathrm{~h}^{-1}$; this should last for at least $6 \mathrm{~h}$. According to such a definition, $\mathrm{I}_{\mathrm{h}}$ and $R_{t}$ can be calculated in a real-time way from the rainfall record. Meanwhile, $R_{t}$ and $\mathrm{I}_{\mathrm{h}}$ can be plotted in a graph with $x$ and $y$ axes. Rainfall records with or without landslide occurrences can be shown in this graph (Fig. 4). Subsequently, the method proposed by Jan et al. (2002) was successfully applied in Shanxi, China, for forecasting landslide occurrence by Zhuang et al. (2014). Thus, improvements and modifications have been presented in this study, and then the rainfall thresholds for shallow landslides can be determined as in the following.

\subsubsection{The lower envelope of landslide occurrence}

A line with a gradient (-a) is drawn under the lowest points which represent landslide occurrences under such rainfall conditions. This is shown with a blue line in Fig. 4. The area between the blue line and the $x$ and $y$ axes defines combinations of $R_{t}$ and $\mathrm{I}_{\mathrm{h}}$ with a zero probability of landslide occurrence. Generally, a coefficient is provided within $10 \%$ for a conservative consideration. Then, the probability of landslide occurrence is defined as PLO $=10 \%$.

\subsubsection{The upper envelope of landslide occurrence}

Similarly, a line with the same gradient can be drawn above the highest points, representing combinations of $R_{t}$ and $\mathrm{I}_{\mathrm{h}}$ without the occurrence of landslides, as shown with a red line in Fig. 4. The area above the red line represents combinations of $R_{t}$ and $\mathrm{I}_{\mathrm{h}}$ with a $100 \%$ probability of landslide occurrence. If the same coefficient is considered for the upper envelope, then $\mathrm{PLO}=90 \%$.

\subsubsection{The algorithm for each probability line}

In the area between the lower envelope (blue line) and the upper envelope (red line), probability lines can be defined by the same method (Fig. 4). The algorithm for each probability line is shown in Eq. (1).

$R_{t}+a I_{\mathrm{h}}=C$,

where $R_{t}$ is the accumulated precipitation $(\mathrm{mm}), I_{\mathrm{h}}$ is the hourly rainfall intensity $\left(\mathrm{mm} \mathrm{h}^{-1}\right)$, and $C$ is a numerical constant.

According to Eq. 1, there must be two constants $C_{\min }$ and $C_{\max }$, corresponding to the lower envelope and the upper envelope respectively. There is an uncertain value, $C$, in the area between the $C_{\min }$ and $C_{\max }$. The relationship between the value $C$ and the probability of landslide occurrence (PLO) can be calculated by Eq. (2).

$\frac{C-C_{\min }}{C_{\max }-C_{\min }}=\left(\frac{\mathrm{PLO}-0}{1-0}\right)^{2}=\mathrm{PLO}^{2}$

Equation (2) can be changed to Eq. 3 for a better understanding.

$C=C_{\min }+\left(C_{\max }-C_{\min }\right) \times \mathrm{PLO}^{2}=C_{\min }+\Delta C \times \mathrm{PLO}^{2}$.

Then, a line for each probability for shallow landslide occurrence can be drawn in the graph by Eq. (3), as shown in Fig. 4.

\subsubsection{Modification and application in the Huangshan region}

While drawing the first probability line (blue line), the gradient (-a) is an uncertain parameter, dependent on experts' experiences or on historical data sets (Jan et al., 2002). To deal with this problem, another parameter $(W)$ has been defined in this study as shown in Eq. (4).

$W=\sqrt{\left(R_{t}\right)^{2}+\left(I_{\mathrm{h}}\right)^{2}}$,

where $R_{t}$ is the accumulated precipitation of one rainfall record $(\mathrm{mm})$ and $I_{\mathrm{h}}$ is the hourly rainfall intensity $\left(\mathrm{mm} \mathrm{h}^{-1}\right)$. So, $W$ represents a combination of the influence from both rainfall factors on landslide occurrence. 
Table 2. Recommended warning levels and responses.

\begin{tabular}{lll}
\hline Warning level & Definition & Response \\
\hline I & $\begin{array}{l}\text { The point calculated from real-time rainfall } \\
\text { monitoring data is in the blue area. }\end{array}$ & Zero: but data are checked daily; monthly monitoring bulletin \\
\hline II & $\begin{array}{l}\text { The point calculated from real-time } \\
\text { rainfall monitoring data is in the yellow area. }\end{array}$ & $\begin{array}{l}\text { Outlook: data are checked daily; } \\
\text { weekly monitoring bulletin }\end{array}$ \\
\hline III & $\begin{array}{l}\text { The point calculated from real-time } \\
\text { rainfall monitoring data is in the orange area. }\end{array}$ & $\begin{array}{l}\text { Attention: data are checked more frequently; daily monitoring bulletin; } \\
\text { authorities and experts are alerted; preparing for alarm }\end{array}$ \\
\hline IV & $\begin{array}{l}\text { The point calculated from real-time } \\
\text { rainfall monitoring data is in the red area. }\end{array}$ & $\begin{array}{l}\text { Warning: data are checked even more frequently; two monitoring } \\
\text { bulletins per day; local population is alerted }\end{array}$ \\
\hline
\end{tabular}

Based on the results from Eq. (4), the lowest five available points of rainfall records with landslide occurrence, in a descending sequence, can be selected to determine the gradient (-a) of the lower curve by the least squares method, as shown in Fig. 5. For a safe landslide early warning in the Huangshan region, the probability of the lower curve is defined as PLO $=10 \%\left(C_{10}\right)$, and the probability of the upper curve is defined as PLO $=90 \%\left(C_{90}\right)$. Each probability line between them can be calculated with Eq. (5).

$C=C_{10}+\left(C_{90}-C_{10}\right) \times \frac{(\mathrm{PLO}-0.1)^{2}}{0.64}$.

When $\mathrm{PLO}=10 \%$, in Fig. 4, the formula of the lower curve is $R_{t}+13.5 I_{\mathrm{h}}=200$, thus $C_{10}=200$; and when $\mathrm{PLO}=90 \%$, the formula of the upper curve is $R_{t}+13.5 I_{\mathrm{h}}=$ 600 , thus $C_{90}=600$. Then, Eq. 5 can be modified into Eq. (6).

$C=200+400 \times \frac{(\mathrm{PLO}-0.1)^{2}}{0.64}$,

where PLO is between 0.1 and 0.9. Based on Eq. 6, each probability line for rainfall-induced landslide occurrence can be drawn in the graph.

There are eight points of landslides in the area that occurred where PLO $=10-50 \%\left(C_{10-50}\right)$, as shown in Fig. 4, and 30 points in the area where PLO $=10-90 \%\left(C_{10-90}\right)$. The ratio between $C_{10-50}$ and $C_{10-90}$ is $26.7 \%$, which is less than $30 \%$, indicating that the points located in this area show a low possibility of landslide occurrence, which also proves that the method is reliable enough for initial application. When more data become available, they will make the method more accurate and more suitable for shallow landslide early warning.

\section{Example of application}

According to the national standard, a four-level early warning scheme (zero, outlook, attention, and warning) is defined for rainfall-induced shallow landslides in the Huangshan region. Additionally, in order to improve the effectiveness of

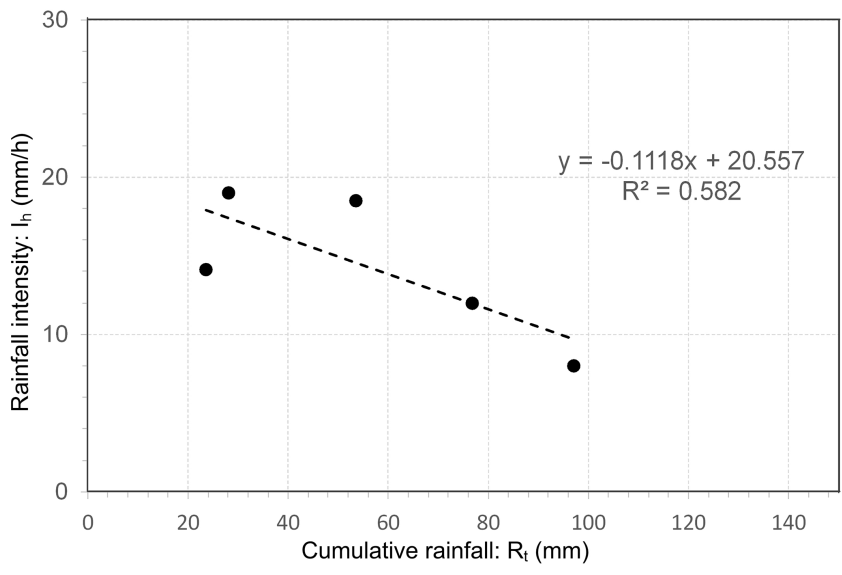

Figure 5. Improved method to ensure the gradient of the lower envelope.

an EWS, the response of the population living in this study area needs to taken into consideration. We reference successful examples, e.g., Baum and Godt (2009); Guzzetti et al. (2007b); Segoni et al. (2015); and Frigerio et al. (2014). A corresponding four-color-coded scale (blue, yellow, orange, and red) of warning levels is shown in Figs. 4 and 6, and in Table 2. In a real-time early warning system, the points (Rt, Ih) are calculated from the rainfall monitoring data by $1 \mathrm{~h}$ per circle in a real-time way while the rainfall starting, which enables a tendency line to be drawn in the early warning graph (Fig. 6).

It can be seen in Fig. 4 and Table 2, that the probability of landslide occurrence in the blue area is less than $10 \%$, indicating that landslides are very unlikely to occur. At this probability level, no warning will be given to the local authorities or the population, but general inspection and regular rainfall monitoring must be carried out, and experts must be informed that they need to pay attention to the rainfall variation. The probability in the yellow area is $10-50 \%$, indicating that there is a possibility of landslide occurrence in the near future. Meanwhile, the local authorities and population will be informed immediately that they must pay close at- 

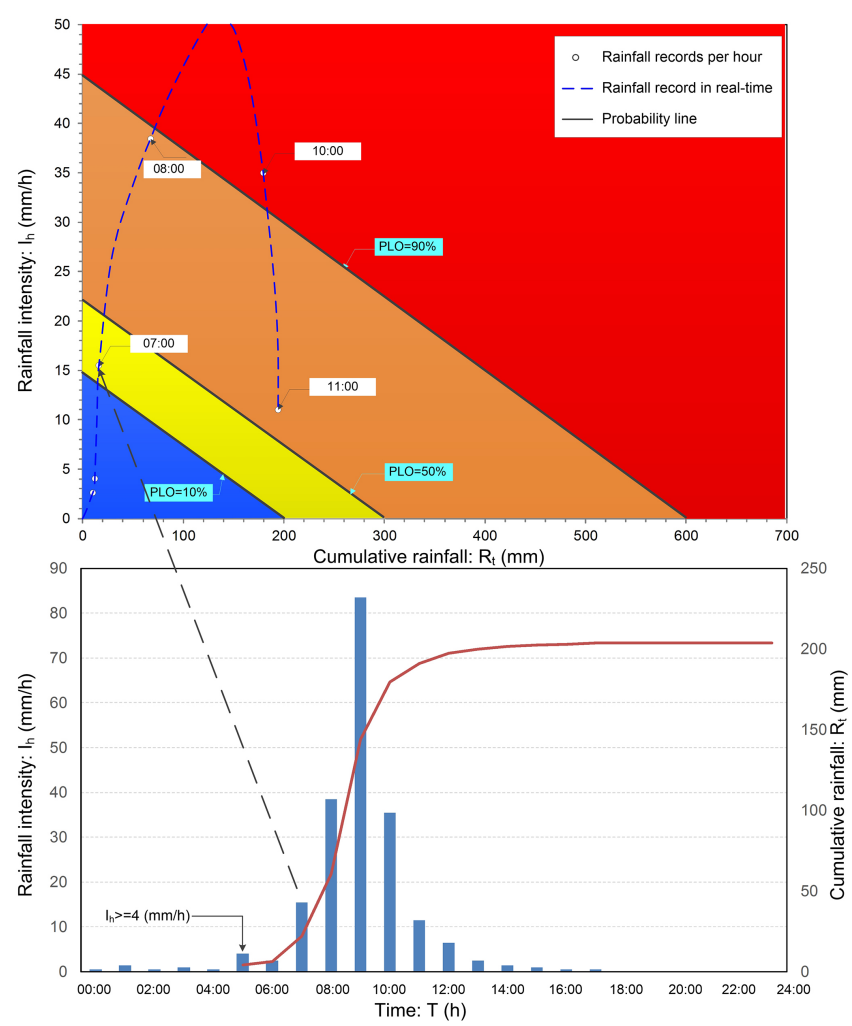

Figure 6. Application of the methodology in the Huangshan region (rainstorm of 30 June 2013).

tention to the rainfall variation. The probability in the orange area is $50-90 \%$, indicating that there is a serious possibility of landslide occurrence in the near future. Therefore, countermeasures and recommendations need to be discussed, e.g., to avoid going to the threatened area. The probability in the red area is more than $90 \%$, indicating that there is a very great chance of landslide occurrence in the hours following. Therefore, local people must be alerted to evacuate the threatened area or avoid going there, and keep a safe distance.

When rainfall occurs, the starting time of the critical rainfall event $\left(\mathrm{I}_{\mathrm{h}}>4 \mathrm{~mm} \mathrm{~h}^{-1}\right)$ must be determined first, then the values of the accumulative rainfall $\left(R_{t}\right)$ and the rainfall intensity $\left(I_{\mathrm{h}}\right)$ can be calculated from the rainfall record and plotted in the graph (Fig. 6). The corresponding alert level can be read from the diagram in a consistent and completely automated way in a landslide early warning system. To demonstrate the application of the above-mentioned method, we present a heavy rainfall record as a case study (Fig. 6), which is also helpful for the improvement of the preliminary rainfall threshold curves. On 30 June 2013, a heavy rainstorm occurred in the Huangshan region, mainly concentrated in $2 \mathrm{~h}$ from 08:30 to 10:30 UTC +8 . The total cumulative rainfall reached $207.5 \mathrm{~mm}$, and the hourly maximum rainfall intensity reached $83.5 \mathrm{~mm} \mathrm{~h}^{-1}$, which is likely to happen less than once a century in this area. Triggered by this heavy rainstorm, many shallow landslides and debris flows occurred, which caused the death of four persons, the disappearance of two persons and a great economic loss.

Figure 6 shows that the rainfall started at midnight on 29 June 2013 , and the hourly rainfall intensity was more than $4 \mathrm{~mm} \mathrm{~h}^{-1}$ at 05:00 on 30 June. From this moment onwards, points with $R_{t}$ and $I_{\mathrm{h}}$ were calculated for every hour and plotted into the diagram. The point at 07:00 just crossing the blue line is located in the yellow area in Fig.6. Due to the fast increase of the rainfall intensity, the yellow area was crossed in a very short time after 07:00 and the 08:00 point is very close to the red line. Incredibly at 09:00, the point is outside the diagram area, due to the fact that the rainfall intensity exceeded all historical records. At 10:00 the point is down in the diagram again. Field investigations after the rainstorm have shown that the catastrophic landslides and debris flows mainly occurred between 8:00 and 10:00. If the alert message had informed local people before 08:00, fewer persons would have been killed or hurt.

In a previous early warning system of this region, there was only a single value $(150 \mathrm{~mm})$ of cumulative rainfall as the warning threshold. The warning message would have been sent at 09:00 approximately. Compared to the improved method presented in this paper (alert message can be sent while the point was in yellow area at 07:00, as shown in Fig. 6), there would be more than $2 \mathrm{~h}$ left for crisis preparation by using the presented warning thresholds. We can conclude that the threshold lines facilitate the prediction of occurrences of rainfall-induced shallow landslides, which is useful for landslide prevention and mitigation at an early stage. Moreover, the rainfall threshold curves can be improved when more data are collected in the future.

\section{Discussion and conclusion}

Landslides induced by rainfall cause significant harm, both in terms of human casualties and economic losses in the vast mountainous areas in China. So, there is an urgent need for effective measures for landslide early warning and mitigation. However, problems in defining regional rainfall threshold values were always encountered during studies, due to the lack of available rainfall and landslide data. Based on the result of previous research by other authors, in this paper we selected the hourly rainfall intensity and the accumulated precipitation as the two rainfall factors in order to overcome these difficulties. The Huangshan region was selected as the study area for the explanation of this methodology. The results of this application show that it is indeed a suitable approach for investigating shallow landslides triggered by rainfall.

However, when using this method, one has to be aware of some limitations and restrictions. The basic limitation is that rainfall thresholds inevitably just represent a simplification of the relationship between rainfall and landslide occurrence (Reichenbach et al., 1998). Usually, when a land- 
slide happens, there is more than one causative factor and the analysis is a complex procedure. The second issue is that the rainfall thresholds presented in this paper have a usage limitation for only the Huangshan region. These limitations must be considered before applying the methodology to another area. Therefore, the determination of rainfall threshold values for landslide early warning must be regarded as a longterm research activity before it can be used as a more reliable approach in the future.

In spite of these limitations, this method of establishing rainfall threshold values from limited data sets provides a way of improving and modifying the method by collecting new data during subsequent studies to reduce the losses caused by this type of natural disaster.

Acknowledgements. This study was financially supported by the State Key Laboratory of Geo-hazard Prevention and Geoenvironment Protection (Chengdu University of Technology) (grant no. SKLGP2013Z007) and the National Natural Science Foundation of China (grant no. 41302242). The authors also give great thanks to Prof. Niek Rengers for his kind advice and for polishing the language, which greatly improve the quality of the manuscript.

Edited by: F. Catani

Reviewed by: two anonymous referees

\section{References}

Aleotti, P.: A warning system for rainfall-induced shallow failures, Eng. Geol., 73, 247-265, doi:10.1016/j.enggeo.2004.01.007, 2004.

Baum, R. and Godt, J.: Early warning of rainfall-induced shallow landslides and debris flows in the USA, Landslides, 7, 259-272, doi:10.1007/s10346-009-0177-0, 2009.

Cannon, S., Gartner, J., Wilson, R., Bowers, J., and Laber, J.: Storm rainfall conditions for floods and debris flows from recently burned areas in southwestern Colorado and southern California, Geomorphology, 96, 250-269, doi:10.1016/j.geomorph.2007.03.019, 2008.

Carey, J. and Petley, D.: Progressive shear-surface development in cohesive materials; implications for landslide behaviour, Eng. Geol., 177, 54-65, doi:10.1016/j.enggeo.2014.05.009, 2014.

David, K., Raymond, C., Robert, K., Earl, E., William, M., Stephen, D., Edwin, L., Gerald, F., Christopher, S., and Robert, S.: RealTime Landslide Warning during Heavy Rainfall, Science, 238, 921-925, 1987.

Frigerio, S., Schenato, L., Bossi, G., Cavalli, M., Mantovani, M., Marcato, G., and Pasuto, A.: A web-based platform for automatic and continuous landslide monitoring: The Rotolon (Eastern Italian Alps) case study, Comp. Geosci., 63, 96-105, doi:10.1016/j.cageo.2013.10.015, 2014.

Glade, T., Crozier, M., and Smith, P.: Applying probability determination to refine landslide-triggering rainfall thresholds using an empirical "Antecedent Daily Rainfall Model”, Pure Appl. Geophys., 57, 1059-1079, 2000.
Greco, R., Giorgio, M., Capparelli, G., and Versace, P.: Early warning of rainfall-induced landslides based on empirical mobility function predictor Eng. Geol. 153, 68-79, doi:10.1016/j.enggeo.2012.11.009, 2013.

Guo, X., Cui, P., and Li, Y.: Debris flow warning threshold based on antecedent rainfall: A case study in Jiangjia Ravine, Yunnan, China, J. Mountain Sci., 10, 305-314 doi:10.1007/s11629-0132521-z, 2013.

Guzzetti, F., Peruccacci, S., Rossi, M., Stark, C.P.: The rainfall intensity - duration control of shallow landslides and debris flows: an update, Landslides, 5, 3-17, doi:10.1007/s10346-007-0112-1, 2007a.

Guzzetti, F., Peruccacci, S., Rossi, M., Stark, C.P.: Rainfall thresholds for the initiation of landslides in central and southern Europe, Meteorol. Atmos. Phys., 98, 239-267, doi:10.1007/s00703007-0262-7, 2007b.

Hong, Y., Hiura, H., Shino, K., Sassa, K., Suemine, A., Fukuoka, H., and Wang, G.: The influence of intense rainfall on the activity of large-scale crystalline schist landslides in Shikoku Island, Jpn. Lands., 2, 97-105, doi:10.1007/s10346-004-0043-z, 2005.

Intrieri, E., Gigli, G., Mugnai, F., Fanti, R., and Casagli, N.: Design and implementation of a landslide early warning system, Eng. Geol., 147-148, 124-136, doi:10.1016/j.enggeo.2012.07.017, 2012.

Jan, C., Lee, M., and Huang, T.: Rainfall Threshold Criterion for Debris-Flow Initiation, National Cheng Kung University, 91049112, 2002.

Jibson, R.: Landslide hazards at La Conchita, California, Geol. Surv., Open File Report 2005-1067, 2005.

Ju, N., Zhao, J., Deng, H., Huang, R., Duan, H.: Analysis of Deformation Mechanism of Sliding to Bending Slope and Study of Deformation Emergency Control at Huangshan Expressway [J], Adv. Earth Sci., 23, 474-480, 2008.

Osanai, N., Shimizu, T., Kuramoto, K., Kojima, S., and Noro, T.: Japanese early-warning for debris flows and slope failures using rainfall indices with Radial Basis Function Network, Landslides, 7, 325-338, doi:10.1007/s10346-010-0229-5, 2010.

Pellicani, R., Frattini, P., and Spilotro, G.: Landslide susceptibility assessment in Apulian Southern Apennine: heuristic vs. statistical methods, Environ. Earth Sci., 72, 1097-1108, doi:10.1007/s12665-013-3026-3, 2014.

Reichenbach, P., Cardinali, M., De, V. P., and Guzzetti, F.: Regional hydrological thresholds for landslides and floods in the Tiber River Basin (central Italy), Environ. Geol., 35, 146-159, 1998.

Segoni, S., Rosi, A., Rossi, G., Catani, F., and Casagli, N.: Analysing the relationship between rainfalls and landslides to define a mosaic of triggering thresholds for regional-scale warning systems, Nat. Hazards Earth Syst. Sci., 14, 2637-2648, doi:10.5194/nhess-14-2637-2014, 2014.

Segoni, S., Battistini, A., Rossi, G., Rosi, A., Lagomarsino, D., Catani, F., Moretti, S., and Casagli, N.: Technical Note: An operational landslide early warning system at regional scale based on space-time variable rainfall thresholds, Nat. Hazards Earth Syst. Sci., 15, 853-861, doi:10.5194/nhess-15-853-2015, 2015.

Tang, C., Rengers, N., van, Asch T., Yang, Y., and Wang, G.: Triggering conditions and depositional characteristics of a disastrous debris flow event in Zhouqu city, Gansu Province, northwestern China, Nat. Hazards Earth Syst. Sci., 11, 2903-2912 doi:10.5194/nhess-11-2903-2011, 2011. 
Thiebes, B.: Integrative Early Warning, in: Landslide Analysis and Early Warning Systems, Springer-Verlag Berlin Heidelberg, 215-219, 2012.

Wei, L., Lee, C., Huang, C., Huang, W., Lin, H., and Chi, C.: A Prelimilary Study of the Rainfall Threshold and Early Warning System for Landslide in Taiwan, in: Engineer Geology for Society and Territory-Volume 2, Springer International Publishing Switzerland, 1571-1574, 2015.

Wooten, R., Gillon, K., Witt, A., Latham, R., Douglas, T., Bauer, J., Fuemmeler, S., and Lee, L.: Geologic, geomorphic, and meteorological aspects of debris flows triggered by Hurricanes Frances and Ivan during September 2004 in the Southern Appalachian Mountains of Macon County, North Carolina (southeastern USA), Landslides, 5, 31-44, doi:10.1007/s10346-0070109-9, 2007.
Zêzere, J., Vaz, T., Pereira, S., Oliveira, S., Marques, R., and Garcia, R.: Rainfall thresholds for landslide activity in Portugal: a state of the art, Environ. Earth Sci., 73, 2917-2936, doi:10.1007/s12665014-3672-0, 2015.

Zhuang, J., Iqbal, J., Peng, J., and Liu, T.: Probability prediction model for landslide occurrences in Xi'an, Shaanxi Province, China, J. Mountain Science, 11, 345-359, 2014. 